\title{
Elevated vascular resistance and afterload reduce the cardiac output response to dobutamine in early growth-restricted rats in adulthood
}

\author{
Vladislava Zohdi ${ }^{1}$, M. Jane Black ${ }^{1}$ and James T. Pearson ${ }^{2 *}$ \\ ${ }^{1}$ Department of Anatomy and Developmental Biology, Monash University, Clayton, VIC, Australia \\ ${ }^{2}$ Department of Physiology and Monash Centre for Synchrotron Science, Building 13F, Monash University, Clayton, \\ VIC 3800, Australia \\ (Received 1 December 2010 - Revised 27 January 2011 - Accepted 9 February 2011 - First published online 1 June 2011)
}

\section{Abstract}

Epidemiological studies have linked intra-uterine growth restriction (IUGR) with an increased risk of CVD later in life. The aim of the present study was to examine the effect of maternal protein restriction on cardiac function in adulthood during dobutamine (DOB) stimulation. IUGR was induced in Wistar Kyoto dams through administration of a low-protein diet (LPD; $8.7 \%$ casein) during pregnancy and lactation; the control group received a normal-protein diet (NPD; $20 \%$ casein). At 14 weeks of age, cardiac function was assessed in male and female NPD (eight females and eight males) and LPD offspring (ten females and ten males) by pressure volumetry using an anaesthetised closed-chest approach. We determined mean arterial pressure (MAP), heart rate and left ventricular pressure-volume indices under baseline conditions and DOB stimulation ( 2 and $4 \mu \mathrm{g} / \mathrm{kg}$ per min). During $\beta$-adrenergic activation in LPD offspring, increases in cardiac output $(\mathrm{CO}, P<0.018)$ and stroke volume (SV, $P<0.005)$ were attenuated in comparison with NPD offspring, while increases in ejection fraction and the maximal rate of ventricular pressure development were not affected. LPD females maintained a smaller enddiastolic volume $(P<0$.017). MAP did not differ between the groups and did not change significantly during DOB infusion. Arterial elastance and total peripheral resistance decreased in all rats but remained significantly elevated in LPD offspring $(P<0.015$ and $<0 \cdot 01)$. Early growth restriction did not affect ventricular contractility but led to an increased afterload and impaired the ability to increase SV and CO during $\beta$-adrenergic stimulation.

\section{Key words: $\beta$-Adrenergic stimulation: Fetal programming: Maternal protein restriction: Vascular resistance}

Intra-uterine growth restriction (IUGR), which occurs in $4-10 \%$ of all term pregnancies ${ }^{(1)}$, is multifactorial in origin, with genetic and environmental influences adversely having an impact on fetal growth ${ }^{(2,3)}$. Epidemiological studies have shown a clear relationship between low birth weight, due to IUGR, and an increased incidence of CVD later in life ${ }^{(4-6)}$; hence, size at birth is an early indicator of disease risk.

It has been postulated that people born of low birth weight have fewer of the functional units in key organs, such as the heart and kidney, and this is likely to render these vital organs susceptible to disease later in life ${ }^{(7)}$. Recent studies from our laboratory have demonstrated that maternal protein restriction in rats leads to a reduction in heart weight and in the number of cardiomyocytes in the hearts of growthrestricted offspring at birth ${ }^{(8)}$. However, the total number of cardiomyocytes was found to be directly proportional to heart size at 4 weeks of age ${ }^{(9)}$, approximately 2 weeks after cardiomyocyte proliferation has ceased in the rat heart. It is not known whether the cardiomyocyte complement in IUGR hearts is capable of performing normal heart work at maturity; however, one study has shown that adult IUGR hearts have attenuated heart rate (HR) responses to $\beta$-adrenergic stimulation $^{(10)}$.

Importantly, we have shown in our IUGR rat model, where female breeder rats are fed a low-protein diet (LPD) during pregnancy and for 2 weeks during lactation, that there is a significant increase in the level of cardiac fibrosis in female offspring in early adulthood, and that this occurs in the absence of catch-up growth or elevation in blood pressure; here, male offspring were not examined ${ }^{(11)}$. In that study, it was not determined whether cardiac function in early adulthood was affected by the early growth restriction. Therefore, we address this in the present study. Interestingly, others have reported that when a maternal LPD is administered

Abbreviations: CO, cardiac output; DOB, dobutamine; $d P / \mathrm{d} t_{\max }$, maximal rate of ventricular pressure development; $d P / \mathrm{d} t_{\text {min }}$, minimal rate of ventricular pressure development; Ea, arterial elastance; EDV, end-diastolic volume; EF, ejection fraction; HR, heart rate; IUGR, intra-uterine growth restriction; LPD, low-protein diet; LV, left ventricle; NPD, normal-protein diet; PAMP, preload-adjusted maximal power; $P-V$, pressure-volume; SV, stroke volume. 
during the gestation period, or any significant part thereof, there is accelerated postnatal growth associated with hypertension $^{(12,13)}$ and subsequent left ventricle (LV) dysfunction in male offspring ${ }^{(14)}$, but not necessarily in females ${ }^{(15)}$. In this regard, Cheema et al. ${ }^{(14)}$ reported a twofold elevation in LV end-diastolic pressure, increased wall thickness, reduced cardiac output (CO) and decreased maximum rates of contraction and relaxation in male offspring at 40 weeks of age. However, in the weaning period, the same offspring showed significant wall thinning, dilation and severely impaired ejection fraction (EF). Whether the systolic and diastolic impairment observed in the previous study ${ }^{(14)}$ occurs entirely as a consequence of sympathetic overactivation in a compensatory phase of development during early adulthood or, in part, as a result of increased vulnerability of IUGR offspring to ageing is currently unknown.

The aim of the present study was to compare cardiac function in situ at 14 weeks of age in male and female nongrowth-restricted and early growth-restricted offspring (that had been exposed to maternal protein restriction during pregnancy and lactation). In particular, we have examined for the first time the haemodynamic and cardiac responses of the in situ growth-restricted heart during $\beta$-adrenergic activation with low doses of dobutamine (DOB) hydrochloride. To address these aims, we used a Millar pressure-volume $(P-V)$ conductance catheter system, whereby LV $P-V$ loops and arterial blood pressure were recorded in situ, in a closed-chest model, under steady-state conditions before, during and after $\beta$-adrenergic stimulation. Preload reductions in CO by vena caval occlusion provide load-insensitive indices of LV contractility, such as the end-systolic $P-V$ relationship and the maximal rate of ventricular pressure development $\left(\mathrm{d} P / \mathrm{d} t_{\text {max }}\right)$ relationship with the end-diastolic volume (EDV). However, such repeated manipulations might change the extent of cardiac sympathetic activation and loading conditions. In the present study, we were most interested in how loading conditions affect the regulation of $\mathrm{CO}$ by $\beta$-adrenergic activation, and thus load-sensitive indices of systolic and diastolic function were compared.

\section{Experimental methods}

\section{Animals and diet treatment}

Female and male Wistar Kyoto breeder rats (10 weeks old) were obtained from the Australian Resource Centre, Perth, Australia. Female breeders were placed on either a LPD $(8.7 \%$ casein and $15.6 \mathrm{MJ} / \mathrm{kg}$ ) or a normal-protein diet (NPD; $20 \%$ casein and $16 \cdot 1 \mathrm{MJ} / \mathrm{kg}$ ) 2 weeks before pregnancy (to allow them to adapt to the diet), during pregnancy and 2 weeks after birth (diets were commercially available from Specialty Feeds, Glen Forest, WA, Australia). Since cardiomyocyte proliferation is complete by the second week after birth, LPD rats in the present study received a normal diet after proliferation is assumed to have ceased. Female breeders were housed individually and maintained on a $12 \mathrm{~h}$ light $-12 \mathrm{~h}$ dark cycle and at a constant temperature of $21 \pm 1^{\circ} \mathrm{C}$. Food and water were provided ad libitum. At birth, the litters were reduced to eight pups per dam. Only one female and one male offspring from each litter were used for these studies (NPD, eight females/eight males and LPD, ten females/ten males); the remaining siblings were used in further studies and not included here. In order to avoid stress in the dams, the pups were first weighed at postnatal day 4 . Body weight of the offspring was measured daily from day 4 until weaning ( 4 weeks of age) and then once a week until the experimental endpoint (14 weeks of age). Animal care and experimental and surgical procedures were carried out in accordance with the National Health and Medical Research Council of Australia 'Code of practice for the care and use of animals for scientific purposes', and were approved by the Monash University, School of Biomedical Sciences Animal Ethics Committee A (VIC, Australia).

\section{Surgical preparation}

Rat offspring at 14 weeks of age were anaesthetised with sodium pentobarbital $(50 \mathrm{mg} / \mathrm{kg}$, intraperitoneal $)$ to induce general anaesthesia and maintained at supplemental doses thereafter ( $25 \mathrm{mg} / \mathrm{kg}$ per h, intravenous bolus) for the duration of the experiments. The trachea was intubated with a 14 gauge angiocath sheath, and the animals were artificially ventilated with a rodent ventilator (Ugo Basile Model 7025, Comerio, VA, Italy) at rates appropriate for their body size (frequency 50 breaths and tidal volume $1 \mathrm{ml} / 100 \mathrm{~g}$ body weight) by room air enriched with supplemental oxygen (30\% total). Body temperature was maintained at $37^{\circ} \mathrm{C}$ using a thermostatically controlled heating pad. The right jugular vein was catheterised with a polyethylene tube (PE-50) for drug delivery and to continuously deliver Hartmann's solution at 3$4 \mathrm{ml} / \mathrm{h}$ (KD Scientific Infusion Pump, Model 781210, Holliston, MA, USA) to maintain body fluid volume during the experiments. Another polyethylene catheter filled with heparinised saline (100 units/ml) was inserted into the left femoral artery for determination of arterial pressure. An intracardiac $P-V$ catheter (1.4F Model-SPR 838, Millar Instruments, Houston, TX, USA) was inserted via the right carotid artery and advanced into the LV chamber, with the thorax intact, in order to obtain the $P-V$ recordings continuously throughout the experiment ${ }^{(16)}$. Arterial blood pressure and cardiac $P-V$ signals were recorded at a sampling rate of $1 \mathrm{kHz}$ and processed using a Powerlab 16/30 Data Acquisition System (AD Instruments, Bella Vista, NSW, Australia).

\section{Assessment of cardiac function}

At 14 weeks of age, haemodynamic function derived from the left ventricular $P-V$ relationship was assessed under baseline conditions and following stepwise increases in cardiacselective $\beta$-adrenergic stimulation (DOB $2-4 \mu \mathrm{g} / \mathrm{kg}$ per min intravenously) in terminal anaesthetised experiments. DOB infusions were continued at each dose until HR and CO plateaued (about 3-5 min). After approximately $10 \mathrm{~min}$, a post-DOB baseline was recorded. The following parameters were recorded or calculated offline on a beat-to-beat basis during brief periods (about $5 \mathrm{~s}$ ) when the ventilation was 
halted: mean arterial pressure $(\mathrm{mmHg}) ; \mathrm{HR}(\mathrm{bpm}) ; \operatorname{EDV}(\mu \mathrm{l})$; end-systolic pressure $(\mathrm{mmHg})$; stroke volume (SV; $\mu \mathrm{l})$; EF (\%); CO ( $\mathrm{ml} / \mathrm{min})$; preload-adjusted maximal power (PAMP; $\mathrm{mW} / \mu \mathrm{l}^{2}$, determined as maximal power/(EDV $\left.)^{2}\right)$; total peripheral resistance (calculated as mean arterial pressure/CO; $\mathrm{mmHg} / \mathrm{ml}$ ); arterial elastance $(\mathrm{Ea}, \mathrm{mmHg} / \mu \mathrm{l}$ determined as end-systolic pressure/SV). Maximal and minimal rates of ventricular pressure changes during the cardiac cycle $\left(\mathrm{d} P / \mathrm{d} t_{\max }\right.$, $\mathrm{mmHg} / \mathrm{s} ; \mathrm{d} P / \mathrm{d} t_{\min }, \mathrm{mmHg} / \mathrm{s}$ ) and relaxation time constants calculated by the Glantz (Tau-G) method (regression of $\mathrm{d} P$ / $\mathrm{d} t v$. pressure, $\mathrm{ms}$ ) and the Weiss (Tau-W) method (regression of log pressure, ms) were computed using a cardiac $P-V$ analysis program (PVAN 3.5, Millar Instruments, Houston, TX, USA) as described previously ${ }^{(17)}$. At completion of the postDOB baseline measurements, $2-3 \mathrm{ml}$ of blood were collected from the femoral artery cannula. The blood sample from each animal was then used for a post boc calibration of the volume conductance signal to absolute volume $(\mu \mathrm{l})$ after a blood conductance correction (the conductance due to ventricular muscle using the hypertonic saline method) according to the recommended procedure ${ }^{(18)}$. The rats were then killed with a lethal overdose $(150 \mathrm{mg} / \mathrm{kg})$ of sodium pentobarbital, and the hearts were immediately excised. The hearts were trimmed of connective tissue and fat, and then weighed. In different male NPD rats, echocardiography was also used to validate the conductance catheter LV volume calibrations ${ }^{(19)}$. End-systolic and end-diastolic LV volumes were calculated using the Bullet formula $^{(20)}$ with long- and short-axis dimensions obtained by echocardiography in B-mode video.

\section{Statistical analysis}

All haemodynamic parameters were derived from $5 \mathrm{~s}$ averages during brief interruptions in ventilation to reduce respiratory rhythm artefacts during baseline conditions and DOB infusion. Parameters were analysed using SYSTAT version 12.0 (Systat Software, Inc., Chicago, IL, USA). The results are expressed as means with their standard errors of the mean. To compare treatment groups under baseline steady-state contractions, a two-way ANOVA was used with the factors maternal dietary treatment $\left(P_{\mathrm{T}} ; \mathrm{NPD} v\right.$. LPD), sex $\left(P_{\mathrm{S}}\right.$; females $v$. males) and their interactions $\left(P_{\mathrm{T} \times \mathrm{S}}\right)$, followed by Bonferroni's post hoc test. To examine the dose response to DOB between males and females of both dietary treatment groups, a three-way ANOVA was employed with the factors dose of DOB $\left(P_{\mathrm{D}}\right)$, sex $\left(P_{\mathrm{S}}\right)$ and maternal dietary treatment $\left(P_{\mathrm{T}}\right)$ and their twoway and three-way interactions $\left(P_{\mathrm{S} \times \mathrm{T}}, P_{\mathrm{T} \times \mathrm{D}}\right.$ and $\left.P_{\mathrm{S} \times \mathrm{T}} \times \mathrm{D}\right)$. Statistical significance was accepted at $P<0 \cdot 05$. As only one female and one male from each litter were included in each treatment group, no adjustment for the litter of origin was necessary.

\section{Results}

\section{Body weights and heart weights}

Body weight in both female and male LPD offspring was significantly lower (21 and $11 \%$, respectively) at postnatal day 4 when compared with NPD offspring $\left(P_{\mathrm{T}}<0.0001\right.$; Table 1). At 14 weeks of age (early adulthood), female and male LPD offspring remained significantly smaller $\left(P_{\mathrm{T}}<0.0005\right)$ in body mass compared with controls. Not surprisingly, absolute heart weights at 14 weeks of age were also significantly lower $\left(P_{\mathrm{T}}<0.025\right)$ in female and male LPD offspring. Hence, the heart weight:body weight ratio was not significantly different between the dietary treatment groups but was greater in females than in males $\left(P_{\mathrm{S}}<0.0055\right)$. It should be noted that while the heart weight:body weight ratio completely overlapped between the male and female NPD offspring, the same ratio overlapped little in the LPD group.

\section{Pressure-volumetry assessment of cardiac function under baseline conditions}

A comparison of LV function and haemodynamics during steady-state conditions (baseline) between the NPD and LPD offspring is shown in Table 1. At 14 weeks of age, we found little evidence of cardiac dysfunction in LPD offspring under steady-state basal contractions, except a significantly reduced $\operatorname{EDV}\left(P_{\mathrm{T}}<0.02\right)$. There was no evidence of elevation in arterial pressure and the slightly elevated Ea in LPD rats was not significant. Likewise, at baseline, HR, SV, CO, EF and LV pressure at end systole and end diastole did not differ between the treatment groups. Male rats differed significantly from female offspring only in basal maximal and minimal rates of LV pressure changes during the cardiac cycle and in the time relaxation constant $\left(\mathrm{d} P / \mathrm{d} t_{\max }\left(P_{\mathrm{S}}<0.02\right), \quad \mathrm{d} P / \mathrm{d} t_{\min }\right.$ $\left(P_{\mathrm{S}}<0.02\right)$ and Tau-G $\left(P_{\mathrm{S}}<0.009\right)$, respectively). However, there was no significant difference between sexes in Tau-W.

\section{Cardiac function and haemodynamics during and after dobutamine stimulation}

HR increased significantly with increasing doses of DOB in both sexes of the NPD and LPD groups $\left(P_{\mathrm{D}}<0 \cdot 001\right.$; Fig. 1(a) and (b)) and almost completely returned to the baseline state (post-DOB $v$. base, $P<0 \cdot 073$ ), but the response did not differ between the treatment groups.

Female LPD offspring had a significantly lower EDV but not males, in comparison with NPD rats $\left(P_{\mathrm{S} \times \mathrm{T}}<0 \cdot 016\right.$; Fig. 1(c) and (d)). The increasing doses of DOB led to a small but significant decrease in EDV in all offspring $\left(P_{\mathrm{D}}<0.002\right.$; Fig. 1(c) and (d)), which was most pronounced in LPD females $\left(P_{\mathrm{S} \times \mathrm{T}}<0.017\right)$.

Although basal SV did not differ between the treatments (Table 1), the increase in load-sensitive SV was significantly attenuated in LPD offspring of both sexes compared with NPD offspring $\left(P_{\mathrm{T}}<0.005\right.$ and $P_{\mathrm{T} \times \mathrm{D}}<0.064$; Fig. $1(\mathrm{e})$ and (f)). SV in NPD offspring was significantly larger than that in LPD offspring in the post-DOB period $\left(P_{\mathrm{T}}<0.018\right)$. EF increased in all offspring of both the treatment groups in response to the DOB challenge, but not significantly so, due to within-animal variability in the response of males (Fig. 1(g) and (h)). Increasing doses of DOB led to a significant increase in CO in female and male NPD and LPD 
Table 1. Morphometry and basal cardiac function in normal-protein diet (NPD, $20 \%$ ) and low-protein diet (LPD, $8.7 \%$ ) female and male offspring (Mean values with their standard errors of the mean)

\begin{tabular}{|c|c|c|c|c|c|c|c|c|c|}
\hline & \multicolumn{2}{|c|}{ Female NPD } & \multicolumn{2}{|c|}{ Female LPD } & \multicolumn{2}{|c|}{ Male NPD } & \multicolumn{2}{|c|}{ Male LPD } & \multirow[b]{2}{*}{$P$} \\
\hline & Mean & SEM & Mean & SEM & Mean & SEM & Mean & SEM & \\
\hline \multicolumn{10}{|l|}{ Morphometry } \\
\hline Sample size $(n)$ & \multicolumn{2}{|c|}{8} & \multicolumn{2}{|c|}{10} & \multicolumn{2}{|c|}{8} & \multicolumn{2}{|c|}{10} & \\
\hline Neonatal weight at day $4(\mathrm{~g})$ & $6 \cdot 77$ & 0.19 & $5 \cdot 33$ & 0.26 & $6 \cdot 86$ & $0 \cdot 11$ & $6 \cdot 11$ & 0.16 & $\begin{aligned} P_{S} & <0.0336 \\
P_{\mathrm{T}} & <0.0001\end{aligned}$ \\
\hline Body weight at 14 weeks (g) & 231 & 4 & 213 & 3 & 340 & 6 & 316 & 7 & $\begin{array}{c}P_{\mathrm{S}}<0.0001 \\
P_{\mathrm{T}}<0.0005\end{array}$ \\
\hline Heart weight at 14 weeks (mg) & 829 & 50 & 775 & 19 & 1126 & 34 & 1021 & 31 & $\begin{array}{r}P_{\mathrm{S}}<0.0001 \\
P_{\mathrm{T}}<0.025\end{array}$ \\
\hline Heart weight:body weight (mg/g) & 3.59 & 0.21 & 3.65 & 0.11 & 3.31 & 0.06 & 3.23 & 0.05 & $P_{\mathrm{S}}<0.0055$ \\
\hline \multicolumn{10}{|l|}{ Haemodynamics } \\
\hline Heart rate (bpm) & 332 & 20 & 327 & 15 & 347 & 19 & 343 & 15 & NS \\
\hline Cardiac output (ml/min) & 28 & 3 & 24 & 2 & 34 & 4 & 27 & 3 & NS \\
\hline LV end-diastolic volume $(\mu \mathrm{l})$ & 171 & 8 & 140 & 7 & 166 & 8 & 149 & 13 & $P_{\mathrm{T}}<0.02$ \\
\hline Stroke volume $(\mu \mathrm{l})$ & 84 & 7 & 73 & 5 & 95 & 8 & 79 & 7 & NS \\
\hline Arterial elastance $(\mathrm{mmHg} / \mu \mathrm{l})$ & 1.37 & 0.19 & 1.67 & 0.13 & 1.36 & 0.15 & 1.68 & 0.16 & NS \\
\hline Systolic arterial pressure $(\mathrm{mmHg})$ & 97 & 11 & 108 & 8 & 110 & 8 & 116 & 6 & NS \\
\hline Diastolic arterial pressure $(\mathrm{mmHg})$ & 77 & 10 & 92 & 8 & 90 & 8 & 96 & 8 & NS \\
\hline Mean arterial pressure $(\mathrm{mmHg})$ & 88 & 10 & 101 & 8 & 100 & 8 & 105 & 7 & NS \\
\hline Ejection fraction (\%) & 47 & 4 & 49 & 3 & 54 & 4 & 52 & 3 & NS \\
\hline End-systolic pressure $(\mathrm{mmHg})$ & 108 & 11 & 121 & 9 & 123 & 9 & 115 & 8 & NS \\
\hline $\mathrm{d} P / \mathrm{d} t_{\max }(\mathrm{mmHg} / \mathrm{s})$ & 6221 & 553 & 7043 & 528 & 8313 & 685 & 7670 & 424 & $P_{\mathrm{S}}<0.02$ \\
\hline $\mathrm{d} P / \mathrm{d} t_{\min }(\mathrm{mmHg} / \mathrm{s})$ & -6166 & 753 & -6584 & 507 & -8262 & 737 & -7805 & 518 & $P_{\mathrm{S}}<0.02$ \\
\hline Preload-adjusted maximal power $\left(\mathrm{mW} / \mu \mathrm{l}^{2}\right)$ & $12 \cdot 26$ & 1.71 & 20.72 & 3.71 & $19 \cdot 19$ & 3.08 & 18.97 & 2.47 & NS \\
\hline Tau-W (ms)* & $10 \cdot 88$ & 0.61 & 11.32 & 0.56 & $10 \cdot 19$ & 0.47 & 10.74 & 0.41 & NS \\
\hline Tau-G $(\mathrm{ms})^{*}$ & $17 \cdot 21$ & 0.85 & 17.41 & 0.92 & 13.76 & 0.92 & $15 \cdot 94$ & 0.79 & $P_{\mathrm{S}}<0.009$ \\
\hline
\end{tabular}

$\mathrm{S}$, sex; T, treatment; bpm, beats per minute; $\mathrm{LV}$, left ventricle; $\mathrm{d} P / \mathrm{d} t_{\max }$, maximal rate of ventricular pressure change; $\mathrm{d} P / \mathrm{d} t_{\min }$, minimal rate of ventricular pressure change; Tau-W, Glantz method; Tau-G, Weiss method. Mean values were significantly different with respect to sex and treatment $(P<0.05)$.

Tau represents the relaxation time constant for ventricular pressure. 
offspring $\left(P_{\mathrm{D}}<0.001\right.$; Fig. 1(i) and (j)), but the rate of increase was significantly depressed in LPD rats $\left(P_{\mathrm{T} \times \mathrm{D}}<0.024\right)$. There was a strong trend for the depression of CO in LPD rats in the post-DOB period (post-DOB $v$. base, $P_{\mathrm{T}}<0.055$ ).

Increasing doses of DOB led to a significant decrease in Ea in all female and male offspring $\left(P_{\mathrm{D}}<0.001\right.$; Fig. $1(\mathrm{k})$ and (1)). However, Ea was significantly elevated in the LPD treatment group $\left(P_{\mathrm{T}}<0.015\right)$, indicating that ventricular afterload was higher in growth-restricted rats.

Adult offspring did not differ in mean arterial pressure (Fig. 2(a) and (b)), diastolic or systolic pressure at any dose of DOB or during the post-DOB period. End-systolic LV pressure was comparable between the groups, varying between
100 and $125 \mathrm{mmHg}$ before, during and after DOB infusion ( $P_{\mathrm{T}}, P_{\mathrm{D}}$ and $P_{\mathrm{S}}$, all not significant). Nonetheless, in agreement with the elevated Ea found in LPD offspring, total peripheral resistance (Fig. 2(c) and (d)) was significantly elevated in comparison with NPD offspring during DOB infusion $\left(P_{\mathrm{T}}<0.01\right)$ and remained so in the post-DOB period (post-DOB $v$. base, $\left.P_{\mathrm{T}}<0.028\right)$.

While the aforementioned findings indicate that LPD offspring of both sexes had attenuated SV responses to DOB stimulation, diet treatment did not affect $\mathrm{d} P / \mathrm{d} t_{\max }$ and $\mathrm{d} P /$ $\mathrm{d} t_{\text {min }}$ or PAMP. Overall, $\mathrm{d} P / \mathrm{d} t_{\max }$ was significantly higher in males compared with females irrespective of treatment $\left(P_{\mathrm{S}}<0.046\right.$; Fig. 2(e) and (f)). DOB challenge led to a significant
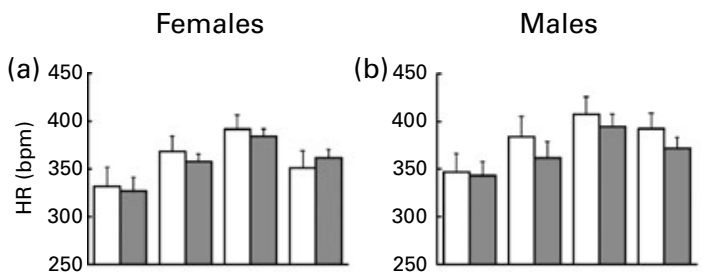

\begin{tabular}{cl}
\multicolumn{1}{c}{$P$} \\
(three-way ANOVA) \\
Main effects & Interactions \\
$P_{\mathrm{D}}<0.001$ & $P_{\mathrm{S} \times \mathrm{T}}<0.035$ \\
$P_{\mathrm{T}} \mathrm{NS}$ & $P_{\mathrm{T} \times \mathrm{D}} \quad \mathrm{NS}$ \\
$P_{\mathrm{S}} \mathrm{NS}$ & $P_{\mathrm{S} \times \mathrm{T} \times \mathrm{D}} \mathrm{NS}$
\end{tabular}

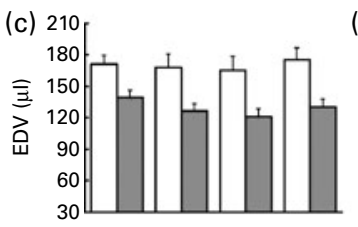

(d) 210

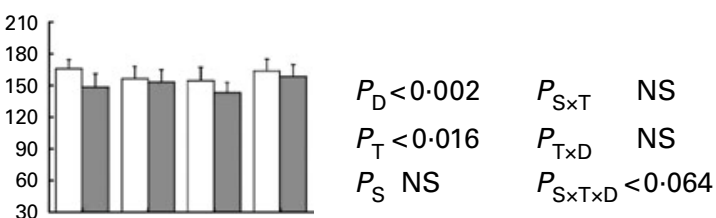

(e)

(f)
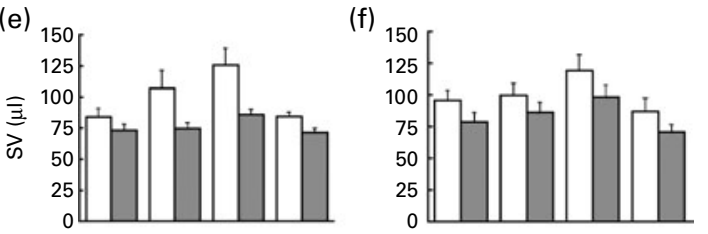
$P_{\mathrm{D}}<0.021 \quad P_{\mathrm{S} \times \mathrm{T}} \quad$ NS
$P_{\mathrm{T}}<0.005 \quad P_{\mathrm{T} \times \mathrm{D}}<0.061$
$P_{\mathrm{S}}$ NS $\quad P_{\mathrm{S} \times \mathrm{T} \times \mathrm{D}} \mathrm{NS}$

(g)

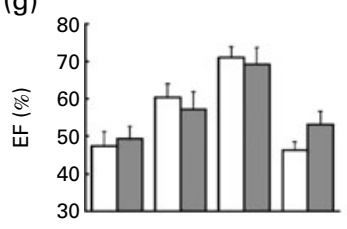

(i)
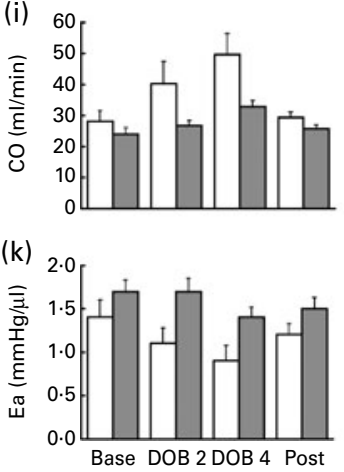

(h)

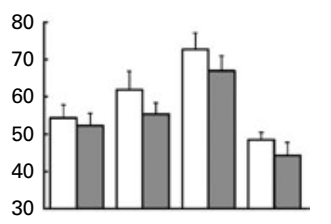

(j)

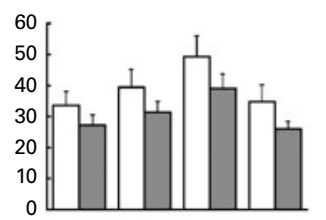

(I)

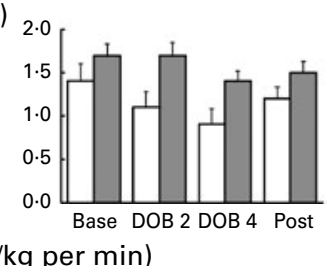

$P_{\mathrm{D}}<0.099$

$P_{\mathrm{S} \times \mathrm{T}}$

NS

$P_{\mathrm{T}} \mathrm{NS}$

$P_{\mathrm{T} \times \mathrm{D}} \quad \mathrm{NS}$

$P_{\mathrm{S}} \mathrm{NS}$

$P_{\mathrm{S} \times \mathrm{T} \times \mathrm{D}} \mathrm{NS}$

$P_{\mathrm{D}}<0.001$

$P_{\mathrm{S} \times \mathrm{T}} \quad \mathrm{NS}$

$P_{\mathrm{T}}<0.018 \quad P_{\mathrm{T} \times \mathrm{D}}<0.024$

$P_{\mathrm{S}}$ NS $\quad P_{\mathrm{S} \times \mathrm{T} \times \mathrm{D}} \mathrm{NS}$

$P_{\mathrm{D}}<0.001$

$P_{\mathrm{T}}<0.015$

$P_{\mathrm{S} \times \mathrm{T}}$

NS

$P_{\mathrm{S}} \mathrm{NS}$

$P_{\mathrm{S} \times \mathrm{T} \times \mathrm{D}}^{\mathrm{T} \times \mathrm{D}} \mathrm{NS}$

Fig. 1. Cardiac function parameters under steady-state baseline, during dobutamine (DOB) infusion (2-4 $\mu \mathrm{g} / \mathrm{kg}$ per min) and the post-DOB (post) period in female and male normal-protein diet (NPD) and low-protein diet (LPD) offspring. (a, b) Heart rate (HR; beats per minute (bpm)), (c, d) end-diastolic volume (EDV), (e, f) stroke volume (SV), ( $g, h)$ ejection fraction (EF), (i, j) cardiac output (CO) and ( $k, l)$ arterial elastance (Ea) in female and male offspring are presented for the NPD $(\square)$ and LPD $(\square)$ treatment groups. Values are means, with standard errors of the mean represented by vertical bars. Mean values were significantly different with respect to maternal diet treatment for NPD or LPD $\left(P_{\mathrm{T}}\right)$, the dose of $\beta$-adrenergic stimulant dobutamine $\left(P_{\mathrm{D}}\right)$, and sex $\left(P_{\mathrm{S}}\right)$ and their interactions $\left(P_{\mathrm{T} \times \mathrm{D}}, P_{\mathrm{S} \times \mathrm{T}}\right.$ and $\left.P_{\mathrm{S} \times \mathrm{D}} ; P<0.05\right)$. 
increase in $\mathrm{d} P / \mathrm{d} t_{\max }\left(P_{\mathrm{D}}<0.001\right)$, but $\mathrm{d} P / \mathrm{d} t_{\text {min }}$ was not significantly changed by DOB $\left(P_{\mathrm{D}}\right.$ not significant; data not shown). There was a tendency for $\mathrm{d} P / \mathrm{d} t_{\text {min }}$ to decrease with dose in female offspring $\left(P_{\mathrm{S}}<0.056\right)$, while $\mathrm{d} P / \mathrm{d} t_{\text {min }}$ was not different from baseline values in males. PAMP increased significantly with the DOB dose $\left(P_{\mathrm{D}}<0 \cdot 001\right.$; Fig. 2(i) and (j)); however, there was a trend for the response to differ between the treatments with respect to $\operatorname{sex}\left(P_{\mathrm{S} \times \mathrm{T}}<0.077\right)$. These findings suggest that neither LV contractility nor relaxation was impaired by LPD treatment.

The relaxation time constants significantly decreased with DOB, Tau-W $\left(P_{\mathrm{D}}<0.001\right)$ and Tau-G $\left(P_{\mathrm{D}}<0.001\right)$ in all offspring (Fig. $2(\mathrm{~g})$ and $(\mathrm{h})$, Tau-G only presented). In both cases, the time constants were longest in LPD offspring $\left(P_{\mathrm{T}}<0.03\right)$ and significantly shorter in male offspring than in females $\left(P_{\mathrm{S}}<0 \cdot 01\right)$.

\section{Normalisation of stroke volume and cardiac output responses to dobutamine stimulation}

Since the preceding analyses indicated that there were differences between the dietary treatment groups in the absolute $\mathrm{SV}$ and CO responses to DOB stimulation and in absolute and relative heart mass, we examined the regulation of $\mathrm{CO}$ after taking into account heart mass (Fig. 3). Group averages for relative $\mathrm{CO}$ and $\mathrm{SV}$ were determined following normalisation according to the heart mass of individual rats. The mean HR of male and female rats overlapped over the DOB dose range examined and did not differ between the treatment groups (Fig. 3(a)). The small difference maintained between the male LPD and NPD rats in absolute SV as the DOB dose increased (Fig. 1(e) and (f)) was entirely explained by the smaller heart mass of LPD rats (Fig. 3(b)). On the other hand, female NPD rats maintained at least a 25\% larger
Females
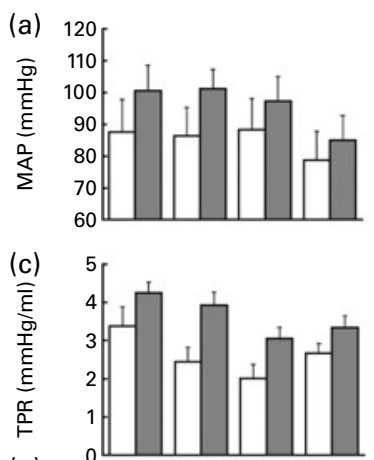

(e)

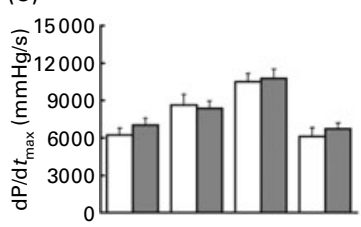

(g)

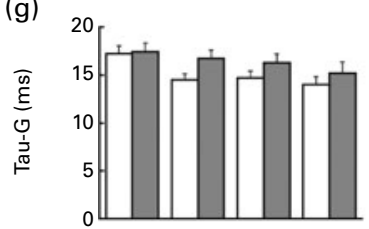

(i)

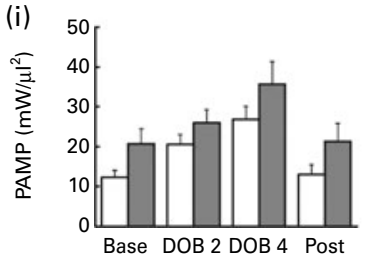

Males

(b) 120

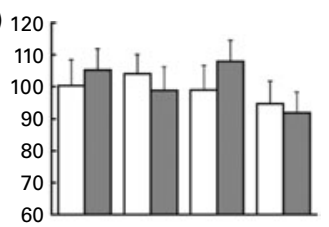

(d)

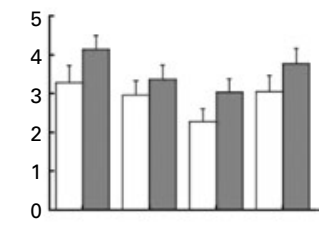

(f)

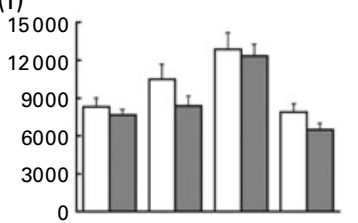

(h)

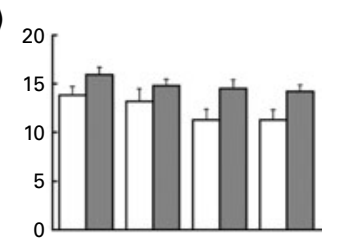

(j)

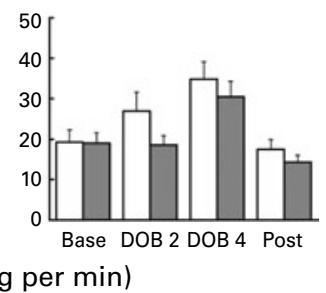

(three-way ANOVA)

Main effects Interactions

$P_{\mathrm{D}}$ NS $\quad P_{\mathrm{S} \times \mathrm{T}} \quad$ NS

$P_{\mathrm{T}}$ NS $\quad P_{\mathrm{S} \times \mathrm{T}} \quad \mathrm{NS}$

$P_{\mathrm{S}}$ NS $\quad P_{\mathrm{S} \times \mathrm{T} \times \mathrm{D}}$ NS

$\begin{array}{lll}P_{\mathrm{D}}<0.001 & P_{\mathrm{S} \times \mathrm{T}} & \text { NS } \\ P_{\mathrm{T}}<0.01 & P_{\mathrm{T} \times \mathrm{D}} & \text { NS } \\ P_{\mathrm{S}} \text { NS } & P_{\mathrm{S} \times \mathrm{T} \times \mathrm{D}} & \mathrm{NS}\end{array}$

$P_{\mathrm{D}}<0.004 \quad P_{\mathrm{S} \times \mathrm{T}} \quad$ NS

$P_{\mathrm{T}}$ NS $\quad P_{\mathrm{T} \times \mathrm{D}} \quad \mathrm{NS}$

$P_{\mathrm{S}}<0.046 \quad P_{\mathrm{S} \times \mathrm{T} \times \mathrm{D}}$ NS

$\begin{array}{lll}P_{\mathrm{D}}<0.001 & P_{\mathrm{S} \times \mathrm{T}} & \mathrm{NS} \\ P_{\mathrm{T}}<0.03 & P_{\mathrm{T} \times \mathrm{D}} & \mathrm{NS} \\ P_{\mathrm{S}}<0.01 & P_{\mathrm{S} \times \mathrm{T} \times \mathrm{D}} & \mathrm{NS}\end{array}$

$P_{\mathrm{D}}<0.001 \quad P_{\mathrm{S} \times \mathrm{T}}<0.077$

$P_{\mathrm{T}}$ NS $\quad P_{\mathrm{T} \times \mathrm{D}} \quad \mathrm{NS}$

$P_{\mathrm{S}}$ NS $\quad P_{\mathrm{S} \times \mathrm{T} \times \mathrm{D}} \mathrm{NS}$

DOB $(\mu \mathrm{g} / \mathrm{kg}$ per $\mathrm{min}$ )

Fig. 2. Cardiac function parameters under steady-state baseline, during dobutamine (DOB) infusion (2-4 $\mu \mathrm{g} / \mathrm{kg}$ per min) and the post-DOB (post) period in female and male normal-protein diet (NPD) and low-protein diet (LPD) offspring. (a, b) Mean arterial pressure (MAP), (c, d) total peripheral resistance (TPR), (e, f) maximal rate of pressure development $\left(\mathrm{d} P / \mathrm{d} t_{\text {max }}\right),(\mathrm{g}, \mathrm{h})$ relaxation time constant of ventricular pressure (Tau-G) and (i, j) preload-adjusted maximal power $(\mathrm{PAMP})$ in female and male offspring are presented for the NPD ( $\square$ ) and LPD ( $\square$ ) treatment groups. Values are means, with standard errors of the mean represented by vertical bars. Mean values were significantly different with respect to maternal diet treatment for NPD or LPD $\left(P_{\mathrm{T}}\right)$, the dose of $\beta$-adrenergic stimulant dobutamine $\left(P_{\mathrm{D}}\right)$, and $\operatorname{sex}\left(P_{\mathrm{S}}\right)$ and their interactions $\left(P_{\mathrm{S} \times \mathrm{T}}, P_{\mathrm{T} \times \mathrm{D}}\right.$ and $\left.P_{\mathrm{S} \times \mathrm{D}} ; P<0.05\right)$. 

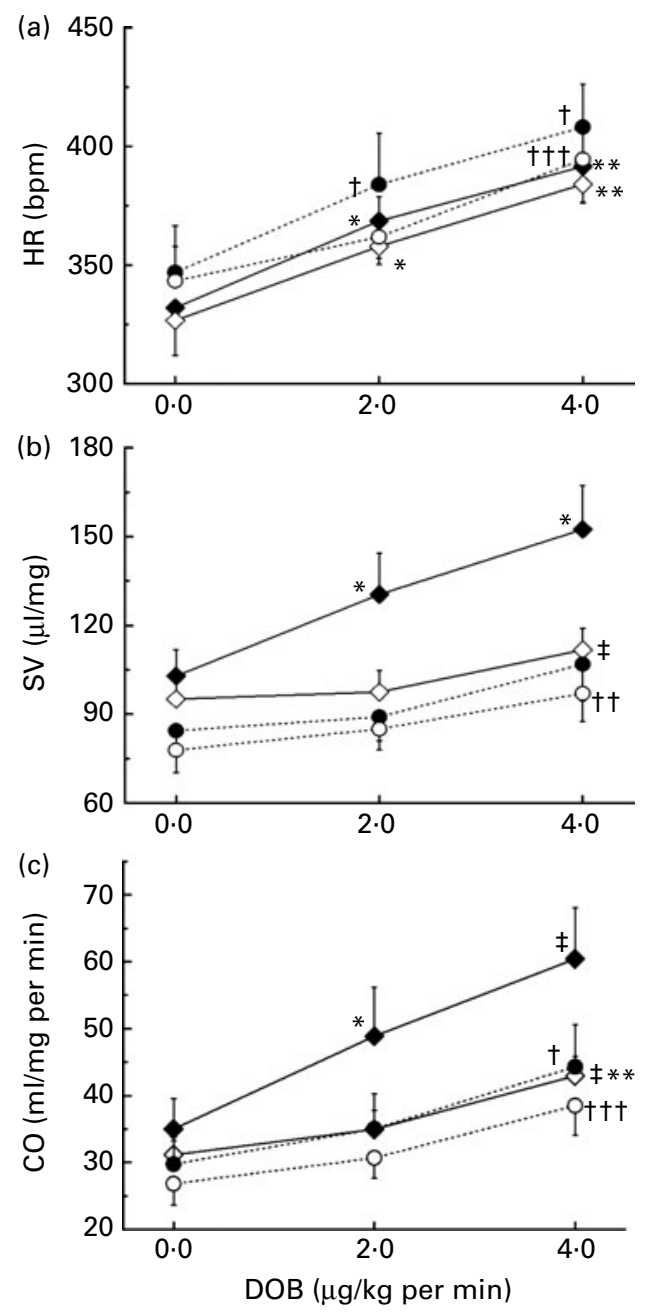

Fig. 3. Heart rate (HR; beats per min (bpm)), stroke volume (SV) and cardiac output (CO) responses to dobutamine (DOB) infusion $(2-4 \mu \mathrm{g} / \mathrm{kg}$ per $\mathrm{min}$ ) following normalisation for heart mass in female and male normalprotein diet (NPD) and low-protein diet (LPD) rats. Mean responses from Fig. 1 are presented for NPD females and males $(\bullet, \bullet)$ and LPD females and males $(\diamond, \bigcirc)$ following normalisation for heart mass in each individual rat. Values are means with their standard errors of the mean. Mean values were significantly different against female baseline: ${ }^{*} P<0.05,{ }^{* *} P<0.01$. Mean values were significantly different against male baseline: $\dagger P<0.05$, $\dagger \dagger P<0.01$, ††† $P<0.001$. $¥$ Mean values were significantly different for LPD females $v$. NPD females $(P<0.001)$.

normalised SV in comparison with male rats and consequently a larger relative CO over male rats at the higher dose of DOB (Fig. 3(c)). In contrast, female LPD rats had mass-specific SV and $\mathrm{CO}$ responses to $\mathrm{DOB}$ that were intermediate between female NPD rats and male rats, and were significantly lower than female NPD rats at the higher DOB dose $(P<0 \cdot 018)$.

\section{Discussion}

The present findings demonstrate that in the absence of accelerated postnatal growth or elevated blood pressure, both male and female IUGR offspring in early adulthood exhibit a reduced capacity to increase CO during $\beta$-adrenergic stimulation. We attribute this impaired ability to increase CO during DOB infusion to an increased afterload in adult LPD offspring acting to reduce the increase in SV. There was no evidence that systolic contractile function was impaired by the early growth restriction in either sex. Even though the increase in afterload was similar in male and female LPD offspring, we can conclude that $\beta$-adrenergic regulation of $\mathrm{CO}$ in female IUGR offspring was more adversely affected than male siblings, as female rats maintain higher $\mathrm{CO}$ relative to heart weight than males. Furthermore, the negative impact of an increased afterload on SV was compounded by a reduced preload in female LPD offspring.

Others have previously examined the effects of another $\beta$-adrenergic agonist, isoprenaline, on HR and LV-developed pressure in the offspring of protein-restricted dams ${ }^{(10,21)}$. Both studies have showed attenuated $\beta$-adrenergic responsivity. However, this is the first study, to our knowledge, that has examined the effects of ventricular loading conditions on the response of the IUGR heart to positive chronotropic and inotropic challenge in adulthood in vivo. While only loadsensitive indices of systolic and diastolic function were examined, the findings clearly demonstrate that growth restriction did not alter cardiac inotropic or chronotropic reserve, but the altered vascular resistance did have a large impact on SV and therefore CO.

The present findings reaffirm that there are sex-specific differences in $\beta$-adrenergic modulation of LV force development and relaxation times in the rat heart at early adulthood, as first reported by Elmes et al. ${ }^{(21)}$. However, we did not find any evidence of sexual dimorphism in the programming of cardiac and haemodynamic dysfunction as a result of IUGR and/or maternal protein restriction, other than a reduced ability to increase LV filling during $\beta$-adrenergic activation in growth-restricted female offspring. Ventricular afterload (Ea) and total peripheral resistance were similarly elevated in both sexes of LPD offspring, suggesting that early growth restriction increased vascular resistance in young adult rats, but not to the extent of developing systemic hypertension. Although many groups have reported hypertension following IUGR $^{(12,13,22)}$, Rodford et al. ${ }^{(23)}$ also reported that neither male nor female early growth-restricted offspring developed hypertension as adults. In contrast to this study, there have been a number of experimental studies reporting differential effects between male and female offspring in response to insults in utero ${ }^{(15,23-31)}$. In contrast to the present findings, it is generally reported that male offspring are more adversely affected.

In the present study, both female and male growthrestricted offspring attained lower body weights at 14 weeks of age compared with NPD controls, indicating that IUGR offspring did not fully catch up in growth when placed on an ad libitum standard laboratory chow 2 weeks after birth; heart weight was in proportion with adult body weight, albeit significantly larger in female rats. Even though IUGR offspring were smaller, basal SV and CO when normalised for heart weight were similar compared with control animals. In support of our findings, Cheema et al. ${ }^{(14)}$ found no differences in EF (assessed by echocardiography) under basal conditions in male (female data reported but not shown) LPD offspring in early adulthood when compared with NPD controls. Interestingly, in that long-term study, there was 
overt cardiac dysfunction at 40 weeks of age as assessed using the $P-V$ method. In this regard, it is likely that more pronounced cardiac dysfunction may also ensue with ageing in our offspring (especially the IUGR females), given that at 14 weeks of age we observed an impaired ability to increase $\mathrm{CO}$ and that systemic vascular resistance was elevated.

In the present study, the hearts of female IUGR offspring were unable to match the SV increase of the hearts of female control offspring during positive inotropic stimulation. All rats demonstrated dose-dependent increases in HR and SV during $\beta$-adrenergic stimulation (Fig. 1(a), (b) and (e), (f), respectively), but notably, in female IUGR offspring, the increase in SV and CO was significantly depressed compared with controls (CO increase of $78 \%$ in NPD $v .64 \%$ in LPD). LV preload decreased during DOB infusion in female IUGR hearts as EDV showed a trend towards larger decreases with the DOB dose, and remained significantly smaller than that of control offspring. The present findings thus demonstrate that in early adulthood (14 weeks of age), only female LPD rats have significantly diminished capacity to increase CO that cannot be accounted for by the smaller heart mass. Indeed, normalising CO and SV to heart mass revealed marked differences in LPD females $v$. NPD females but not in males; HR was on average only $10-20$ bpm lower in LPD males $v$. controls at the doses examined and females were approximately $2-10 \mathrm{bpm}$ lower (Fig. 3(a)). Hence, in male growth-restricted offspring, the diminished $\mathrm{CO}$ response to DOB, at this age at least, appears to be largely attributable to the smaller heart mass rather than the increase in afterload per se.

The reduced ability to increase SV during $\beta$-adrenergic stimulation in female IUGR offspring is unlikely to be attributed to a reduction in $\beta$-adrenergic sensitivity as LPD offspring were equally able to increase HR. Likewise, the reduced blood ejection in female IUGR offspring does not appear to be attributed to a reduced ability to maximally increase force development, as their hearts developed pressure normally. Previously, we have shown that in the rat heart, cross-bridge cycling is essentially completed in the isovolumetric contraction phase $^{(16)}$, and in this study, female LPD hearts did not have impaired rates of force development in this first phase of the $P-V$ relationship. Therefore, cross-bridge cycling and myofilament $\mathrm{Ca}^{2+}$ sensitivity are presumed to be normal in the IUGR heart. The fact that the hearts of LPD female offspring required higher PAMP to attain the same end-systolic pressure and $\mathrm{d} P / \mathrm{d} t_{\max }$ as NPD offspring also argues against abnormal calcium handling in the cardiomyocytes of IUGR females. Rather, the diminished capacity to increase SV appears to be due to diminished preload and impaired fibre shortening in the face of elevated afterload. Further studies are currently determining whether the LV extracellular matrix composition is altered by an early growth restriction.

In conclusion, it is now well established that the antecedents of CVD can be programmed in early life, with IUGR directly linked to an increased risk of adult CVD. The present findings strongly suggest that both the smaller absolute heart mass and the increased afterload reduce the growth-restricted capacity of the heart to increase SV and CO during $\beta$-adrenergic activation in early adulthood.

\section{Acknowledgements}

V. Z., M. J. B. and J. T. P designed the study; V. Z. bred and maintained the rats for the study; V. Z. and J. T. P performed the study and analysed the data; V. Z., M. J. B. and J. T. P wrote the manuscript. The authors declare no conflict of interest. The present study was supported by an Australian Postgraduate Research Award to V. Z., and a Linkage Infrastructure, Equipment and Facilities grant LE0668435 from the Australian Research Council to J. T. P.

\section{References}

1. Beargie RA, James VL Jr \& Greene JW Jr (1970) Growth and development of small-for-date newborns. Pediatr Clin North Am 17, 159-167.

2. Resnik R (2002) Intrauterine growth restriction. Obstet Gynecol 99, 490-496.

3. Wollmann HA (1998) Intrauterine growth restriction: definition and etiology. Horm Res 49, Suppl. 2, 1-6.

4. Barker DJ (1992) The effect of nutrition of the fetus and neonate on cardiovascular disease in adult life. Proc Nutr Soc 51, 135-144.

5. Barker DJ \& Fall CH (1993) Fetal and infant origins of cardiovascular disease. Arch Dis Child 68, 797-799.

6. Law CM, Barker DJ, Richardson WW, et al. (1993) Thinness at birth in a northern industrial town. J Epidemiol Community Health 47, 255-259.

7. Barker DJ, Eriksson JG, Forsen T, et al. (2002) Fetal origins of adult disease: strength of effects and biological basis. Int J Epidemiol 31, 1235-1239.

8. Corstius HB, Zimanyi MA, Maka N, et al. (2005) Effect of intrauterine growth restriction on the number of cardiomyocytes in rat hearts. Pediatr Res 57, 796-800.

9. Lim K, Zimanyi MA \& Black MJ (2010) Effect of maternal protein restriction during pregnancy and lactation on the number of cardiomyocytes in the postproliferative weanling rat heart. Anat Rec (Hoboken) 293, 431-437.

10. Fernandez-Twinn DS, Ekizoglou S, Wayman A, et al. (2006) Maternal low-protein diet programs cardiac beta-adrenergic response and signaling in 3-mo-old male offspring. $\mathrm{Am} \mathrm{J}$ Physiol Regul Integr Comp Physiol 291, R429-R436.

11. Lim K, Zimanyi MA \& Black MJ (2006) Effect of maternal protein restriction in rats on cardiac fibrosis and capillarization in adulthood. Pediatr Res 60, 83-87.

12. Langley-Evans SC, Gardner DS \& Jackson AA (1996) Association of disproportionate growth of fetal rats in late gestation with raised systolic blood pressure in later life. J Reprod Fertil 2, 307-312.

13. Woods LL, Weeks DA \& Rasch R (2004) Programming of adult blood pressure by maternal protein restriction: role of nephrogenesis. Kidney Int 65, 1339-1348.

14. Cheema KK, Dent MR, Saini HK, et al. (2005) Prenatal exposure to maternal undernutrition induces adult cardiac dysfunction. Br J Nutr 93, 471-477.

15. Woods LL, Ingelfinger JR \& Rasch R (2005) Modest maternal protein restriction fails to program adult hypertension in female rats. Am J Physiol Regul Integr Comp Physiol 289, R1131-R1136.

16. Pearson JT, Shirai M, Tsuchimochi H, et al. (2007) Effects of sustained length-dependent activation on in situ crossbridge dynamics in rat hearts. Biophys J 93, 4319-4329.

17. Cingolani $\mathrm{OH}$, Yang XP, Cavasin MA, et al. (2003) Increased systolic performance with diastolic dysfunction in adult spontaneously hypertensive rats. Hypertension 41, 249-254. 
18. Pacher P, Nagayama T, Mukhopadhyay P, et al. (2008) Measurement of cardiac function using pressure-volume conductance catheter technique in mice and rats. Nat Protoc 3, 1422-1434.

19. Marsh SA, Dell'Italia LJ \& Chatham JC (2008) Interaction of diet and diabetes on cardiovascular function in rats. $\mathrm{Am} \mathrm{J}$ Physiol Heart Circ Physiol 296, H282-H292.

20. Dell'Italia LJ, Blackwell GG, Pearce DJ, et al. (1994) Assessment of ventricular volumes using cine magnetic resonance in the intact dog. A comparison of measurement methods. Invest Radiol 29, 162-167.

21. Elmes MJ, Haase A, Gardner DS, et al. (2009) Sex differences in sensitivity to $\beta$-adrenergic agonist isoproterenol in the isolated adult rat heart following prenatal protein restriction. Br J Nutr 101, 725-734.

22. Torrens C, Brawley L, Anthony FW, et al. (2006) Folate supplementation during pregnancy improves offspring cardiovascular dysfunction induced by protein restriction. Hypertension 47, 982-987.

23. Rodford JL, Torrens C, Siow RCM, et al. (2008) Endothelial dysfunction and reduced antioxidant protection in an animal model of the developmental origins of cardiovascular disease. J Physiol 586, 4709-4720.

24. Baserga M, Bares AL, Hale MA, et al. (2009) Uteroplacental insufficiency affects kidney VEGF expression in a model of IUGR with compensatory glomerular hypertrophy and hypertension. Early Hum Dev 85, 361-367.
25. Hemmings DG, Veerareddy S, Baker PN, et al. (2005) Increased myogenic responses in uterine but not mesenteric arteries from pregnant offspring of diet-restricted rat dams. Biol Reprod 72, 997-1003.

26. Jones A, Beda A, Osmond C, et al. (2008) Sex-specific programming of cardiovascular physiology in children. Eur Heart J 29, 2164-2170

27. Khan I, Dekou V, Hanson M, et al. (2004) Predictive adaptive responses to maternal high-fat diet prevent endothelial dysfunction but not hypertension in adult rat offspring. Circulation 110, 1097-1102.

28. Khan IY, Taylor PD, Dekou V, et al. (2003) Gender-linked hypertension in offspring of lard-fed pregnant rats. Hypertension 41, 168-175.

29. Kwong WY, Wild AE, Roberts P, et al. (2000) Maternal undernutrition during the preimplantation period of rat development causes blastocyst abnormalities and programming of postnatal hypertension. Development 127, 4195-4202.

30. Ozaki T, Nishina H, Hanson MA, et al. (2001) Dietary restriction in pregnant rats causes gender-related hypertension and vascular dysfunction in offspring. J Physiol 530, $141-152$.

31. Pascoe KC, Wlodek ME \& Jones GT (2008) Increased elastic tissue defect formation in the growth restricted Brown Norway rat: a potential link between in utero condition and cardiovascular disease. Pediatr Res 64, 125-130. 